\title{
Dramatización en la narrativa del converso*
}

\author{
Patricia Fortuny Loret de Mola \\ CIESAS-OCCIDENTE/CONACYT
}

\begin{abstract}
El objetivo de este documento es destacar la importancia del lenguaje en la conversión religiosa y analizar la forma en que el converso transforma la memoria en la narrativa de la conversión. El creyente recrea y reinventa la memoria a partir de su conversión, que se expresa a través del "lenguaje o retórica religiosa". El uso reiterativo de ésta constituye además un elemento central en el proceso de autoconvencimiento. Ilustro esta discusión con material empírico de casos de conversión a religiones protestantes.
\end{abstract}

"La forma en la que hablamos sobre nuestro pasado y el tipo de preguntas que nos hacemos acerca de éste pueden fácilmente pasar a formar parte de la memoria original."

Donald Spence

\section{INTRODUCCIÓN}

$\mathbf{P}$ ara iniciar mi relato, deseo esclarecer que el caso de conversión que aquí trato, aunque no pretende ser representativo en el sen-

* Este documento está dedicado a la memoria de mi entrañable amigo y compañero de tra- tido del modelo positivista, no corresponde tampoco a un caso aislado de la realidad. En la década de los setenta, específicamente en los estados de la región sureste de nuestro país, la dimensión religiosa que se concibe entretejida con el resto de las dimensiones, social, económica, política y cultural, experimentaba profundas transformaciones. Pese a que ya hacía mâs de 100 años que la religión católica había dejado de ser la única tradición

bajo de campo Carlos Romero Pacheco, quien nos abandonara para siempre desde julio de 1992. 
cristiana presente, en los años setenta tuvo lugar una extraordinaria migración religiosa, en la que miles de católicos se convirtieron a distintos tipos de protestantismos. Como no es posible hablar in extenso sobre la materia, me reduciré a dar los datos sobre el estado de Yucatán, lugar en que se ubica el relato. Una encuesta realizada entre 1981/1982 en los 105 municipios de Yucatán -sin incluir la ciudad capital de Mérida-, reveló la existencia de más de 300 templos evangélicos y paraprotestantes en 103 de los 105 municipios. Es decir, sólo dos poblaciones de Yucatán carecían de disidentes religiosos. Ahora bien, como ni ustedes ni yo creemos en la sola elocuencia de las cifras para explicar los cambios en la historia, pasaremos al nivel de la elocuencia de los sujetos quienes desde su íntima subjetividad revelan lo que los números callan.

La primera parte de este documento es una anécdota que hará una especie de presentación del tema; a continuación introduzco al informante que nos narra en forma dramática su momento de conversión; estos párrafos constituyen mi materia prima para interpretar y reflexionar sobre lo ya reflexionado por el narrador. Para realizar esto, debo confesar que hice uso de una miscelánea de herramientas que incluyen desde luego a la historia oral. En la parte final, despliego en forma más explícita aquellas herramientas y discuto algunas ideas sobre la transformación del lenguaje y de la memoria a la luz de una teoría de la conversión.

\section{INSÓLITO ENCUENTRO}

Corría el año de 1980, un colega y yo visitábamos un pueblo yucateco en el que realizábamos una encuesta -la primera que se hacía en el país-, sobre la presencia de templos protestantes en los municipios de Yucatán. Esto sucedía en el mes de abril, tiempo en que la tierra se calienta y la atmósfera despide densos vapores que hacen transpirar a los habitantes. Agotados por el camino y el calor nos detuvimos a descansar y en eso estábamos cuando un sonriente campesino yucateco nos abordó. Poco después de iniciada nuestra plática supimos que se trataba o bien de un católico poco común o de un evangélico, ya que a lo largo de nuestra breve conversación había invocado a diversos personajes de la Biblia en un sinnúmero de ocasiones. Recuerdo que después de nuestro diálogo, $\mathrm{mi}$ colega y yo comentamos sorprendidos que aquél había sido un encuentro casi surrealista o que quizá el ardiente clima nos había hecho imaginarnos la escena, tan ansiosos que estábamos por encontrar protestantes. Y esto se debía a que en nuestra experiencia anterior, los campesinos hablaban más bien de sus problemas terrenales "muy mundanos", tales como la tierra, el trabajo, la pobreza, las autoridades locales o la familia y la salud. Nuestro primer encuentro con un evangélico significó la revelación, ante nuestros ojos, de un mundo nuevo y desconocido que en los próximos meses descubriríamos como más normal de lo que jamás habíamos imaginado.

Este hecho fortuito, depositado en algún pasaje marginal de mi memoria, 


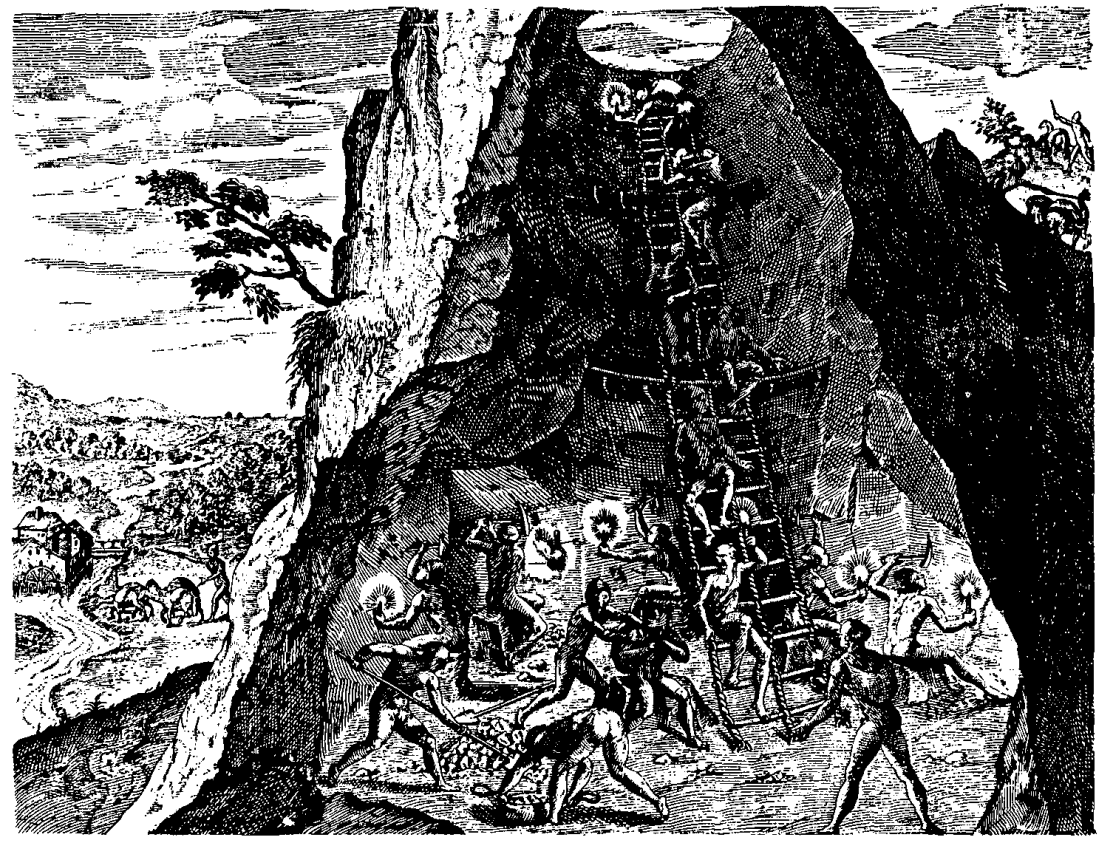

se hizo presente sin embargo muchos años después, cuando empecé a pensar seriamente sobre la importancia que tiene el lenguaje religioso para los conversos. En el caso relatado, este campesino que luego conocimos más de cerca, había usado su retórica religiosa como una tarjeta de presentación personal para destacar frente a nosotros su identidad evangélica positiva y consciente de su ser social.

\section{DRAMATIZACIÓN DEL RELATO}

La porción biográfica que leeré en unos momentos más corresponde a un hombre de 65 años, de origen maya campesino, nacido en Temax, Yucatán, que había vivido hasta los 41 años como un católico más. En ese tiempo conoció el evangelio, dejó su antigua forma de vivir, y se dedicó por siete años a trabajar como sastre y carpintero para mantener a su esposa y ocho hijos, hasta que finalmente lo accptaron de estudiante en un seminario para después hacerse predicador de una iglesia pentecostal: Asamblea de Dios. Cuando lo conocimos, don Eligio sostenía a su esposa y a sus tres hijos menores con su trabajo de ministro religioso, y en ocasiones, para com- 
plementar este ingreso, componía guitarras y hacía algo de carpintería. Dos de sus hijos varones y una hija también eran pastores en ese tiempo. Don Eligio componía pequeños coros religiosos que se cantaban en el templo que él dirigía. Era un hombre respetado $\mathrm{y}$ apreciado por sus virtudes, $\mathrm{y}$ uno de los líderes religiosos protestantes más tolerantes que había en el pueblo. Siempre supo que nosotros los antropológos no éramos convertibles, y a pesar de ello, nunca dejó de sorprendernos con sus sabias respuestas ante los tediosos interrogatorios a que lo sometíamos. En esos ya lejanos días nos contó don Eligio lo siguiente:

Yo era un hombre malo, estaba en el mundo de la hechicería, la magia, mezclaba con la medicina botánica, sacaba la suerte, era malo y ocultaba algo en mí que expresaba que yo no era perfecto en el amor. El hechizo que conocí diabólicamente, nada de que es de comer, sino que el diablo se encarga de hacer los efectos, ya que el diablo es poderoso. Tiene el reino infernal. Dios le dijo que fuera al mundo a ejecutar sus maldades. Dios tenía sus planes, pero el diablo quería apoderarse del mundo, tomar el lugar de Dios.

Un día, hermanos, yo caminaba por las calles de Temax, como en estas horas lluviosas, estaba empapado de loclo, mi cabello mojado de la llovizna. Caminaba yo briago por las calles, olvidado, buscando a quien pedirle dos pesos para continuar mi aguardiente. Pero un día, queridos hermanos, supe la noticia de Jesucristo, que fue limpiando mi conciencia de pecado. Comencé a acercarme a ese Cristo, y comencé a clamarle y le decía: "Cristo, Cristo, si verdaderamente tú estás en la diestra del Padre, si verdaderamente estás ahí sentado para escuchar a todo hombre que vive en el fango de la desgracia, soy uno de ellos, aquí estoy, ve mi situación. ¿Tendrás misericordia de mí? ¿Habrá algún remedio para mí? ¿Podrás cambiar mis pensamientos?" $\mathrm{Y}$ hermanos, el Señor lo hizo...

Y creo que el hombre que escribió la carta a los hebreos [San Pablo] que en esta noche estamos hablando, él mismo lo expresa y lo dice: "Estoy seguro que Jesucristo vino al mundo para salvar a los pecadores, de los cuales yo también soy uno de ellos. En otros tiempos andaba yo persiguiendo a los cristianos. Andaba yo con cartas selladas por aquellos hombres religiosos, para traerlos y entregarlos a las cárceles. Pero un día caminando camino a Damasco, se me apareció una luz gloriosa y caí de rodillas y clamé y dije: Señor, ¿qué quieres que haga?..."

La primera noticia es que yo acepté a Cristo como salvador y que le picliera perdón por lo que fui. Yo vendía talismanes... Hay cosas que uno hace sin darse cuenta y son pecado. Cuando me hablaron que Cristo podría perdonarme y reconciliarme en Dios, acepté. No quise ser enemigo de Dios, sino su amigo. Por eso hoy día me gusta platicar de lo que era. ${ }^{1}$

Para que la hermenéutica tenga sentido, debe realizarse en el marco del contexto en el que se produjo el discurso. El párrafo anterior es un testimonio o narrativa de una conversión que se construye en forma consciente o inconsciente con la finalidad de

${ }^{1}$ Entrevistas realizadas a EG en Buctzotz, Yucatán, en 1980 por el investigador Carlos Romero y la autora de este trabajo. Estas transcripciones fueron parte de un proyecto de investigación más amplio titulado: El Protestantismo en las Comunidades Rurales de Yucatán. 


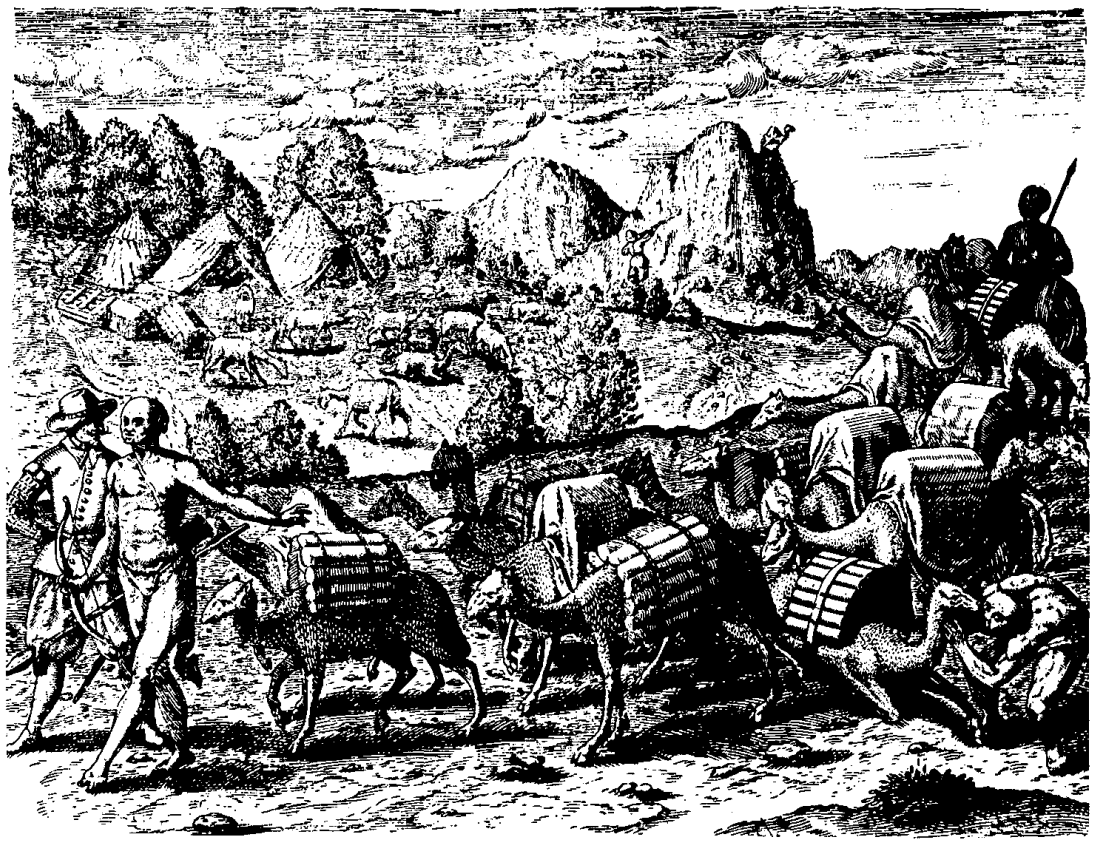

crear un efecto en el que escucha. Para lograr esto, el narrador -experto- utiliza en la producción de su discurso múltiples códigos especiales, metáforas, un lenguaje figurado, poético y simbólico. Encontramos también un patrón constante en este tipo de relatos, que consiste en que al principio el individuo está en la posición del "no salvo" o perdido -el que escucha-, y su deslizamiento a la nueva posición en la que es "salvo", ${ }^{2}$ y ahora

\footnotetext{
${ }^{2}$ En el lenguaje de los conversos, los mismos creyentes se autodesignan "no salvos" para referirse al momento anterior a su conver-
}

es quien habla, o como si su conversión religiosa le hubiera concedido una nueva voz que antes no tenía.

En el primer párrafo don Eligio describe su oficio de hechicero, que aunque objetivamente puede ser de reputación incierta, también ha sido un oficio que otorga estatus y privilegios al que lo practica. Sin embargo, en el relato, el lado positivo del curandero, del hombre sabio en la herbolaria y la botánica está oculto por el pa-

sión, y se llaman "salvos" cuando ya han atravesado esa frontera entre el pecado y la salvación, es decir, cuando son conversos. 
pel de mago protegido por poderes diabólicos. La figura del diablo lo acompaña siempre. En el presente, su antiguo oficio de brujo es explicado sólo en función de la extraordinaria fuerza de lo perverso. El hechicero era, en otras palabras, un instrumento de Lucifer para hacer el mal. Este primer fragmento se inicia con un hablar cotidiano y concluye con frases construidas en un marco de la creencia y de la doctrina: "Dios tenía sus planes".

En el segundo párrafo el creyente expone el punto culminante de su cambio a través de un acto en dos tiempos: el primero se realiza en un escenario trágico que cuenta con elementos que se asocian al mal como el fango, la embriaguez, la marginalidad, la oscuridad, la soledad, la miseria. En el segundo tiempo el arrepentido busca y llama a Dios, lo interroga y tiene un diálogo con él en el cual le suplica misericordia y perdón, pues un evangelista le había dicho que Dios lo perdonaría. Para hacer más efectivo su relato el predicador hace uso de un emotivo y nítido lenguaje religioso mezclado con el hablar cotidiano de forma tal que éste a la vez le permita a sus fieles identificarse con el narrador.

En el tercer párrafo, el creyente se identifica con el profeta Pablo, hace una analogía entre su conversión y la de San Pablo. Ambos caminan, son pecadores, enemigos de los verdaderos cristianos, aliados de Satanás, perdidos, interrogan a Dios sobre qué hacer y Dios los escucha y los redime. Saulo se convierte en San Pablo evangelista y don Eligio pasa del predicamento de ser hechicero a predicador.
El último párrafo es una ratificación de su transformación interna.

\section{REFLEXIONES SOBRE LAS REFLEXIONES}

Los primeros estudios sobre el fenómeno de la conversión fueron realizados por psicólogos y fisiólogos en la primera mitad de este siglo. Estos estudiosos entendían la conversión y la experiencia religiosa -que generalmente implica-, como un estado patológico y la explicaban como algo que le sucede al individuo, y en donde éste es incapaz de reaccionar a esa poderosa fuerza externa que lo absorbe totalmente. ${ }^{3}$ Hacia los años sesenta surgió una explicación distinta a la anterior que ha sido llamada la conversión activa, porque en ésta los sujetos son actores reales de su propio proceso, van en busca de un cambio y, para ello, interactúan en forma permanente con un grupo religioso determinado. Los cambios que experimenta el individuo no terminan con la experiencia religiosa, sino que se producen a lo largo de toda su vida, es por esto que puedo afirmar que la conversión y la construcción de la nue-

\footnotetext{
${ }^{3}$ Los primeros acercamientos al estudio de la conversión estuvieron fuertemente influidos por el relato bíblico de la conversión paulina en la que Saulo de Tarso, cuando iba canino a Damasco, recibe una intensa luz (fuerza externa) que se apodera materialmente de él (experiencia religiosa), y cuando despierta de la impresión, se ha convertido en Pablo, un nuevo cristiano. Los estudiosos utilizaron la experiencia paulina para construir un modelo paradigmático sobre la conversión que luego fue llamado la conversión pasiva. Véase Richardson, "Active", 1985.
} 
va identidad religiosa son efectivamente dos ángulos desde los cuales es posible analizar el mismo fenómeno empírico, y la mejor estrategia para hacerlo es a través de la narrativa del converso.

No estoy de acuerdo con los enfoques sociológicos que "explican" las causas de la conversión a partir de las crisis sociales, el desarraigo cultural o la anomia, ya que éstos dejan fuera al actor real y proporcionan explicaciones demasiado amplias y generales que exhiben el bosque pero ocultan a los árboles. Son explicaciones incompletas e inadecuadas porque no consideran como fuente primaria lo que el mismo sujeto de estudio nos dice en su narrativa, que ha sido construida a partir de la experiencia personal de conversión y de cómo la entiende el propio sujeto. Ésta es la diferencia fundamental entre darle preferencia a una explicación de tipo estructural o a una explicación que incluya la dimensión subjetiva, desde el método fenomenológico. Con esto no quiero decir que no se tome en cuenta la parte estructural (macro) del fenómeno, sino que se le dé su justo lugar. El definir la conversión como un producto causado por la migración a las ciudades, resulta fácilmente disprobado, en virtud de que por un lado, la mayoría de los migrantes no se convierten y, por el otro, un gran sector de los conversos no son migrantes. Con este ejemplo muy esquemático es posible demostrar que para comprender en forma cabal un fenómeno de la naturaleza de la conversión religiosa es absolutamente necesario tener un enfoque que no sólo incluya lo estruc- tural del mismo, sino un enfoque que permita acercarse a la íntima subjetividad del sujeto.

$Y$ es esto último lo que yo he tratado de hacer aquí en forma breve. Porque si la mejor manera de acercarnos al fenómeno de la conversión es a través de la narrativa, el lenguaje utilizado adquiere entonces un lugar central en la discusión, en virtud de que tanto la conversión como la recreación de la identidad implican y requieren de una reelaboración del vocabulario del creyente, una reorganización de su discurso, a través de nuevas conceptualizaciones que se dan en la matriz social o nueva estructura de plausibilidad. Para adquirir ese lenguaje religioso el sujeto interactúa en forma intensa -que tiene mucho de afectiva-, con el nuevo grupo que le proporciona los nuevos referentes que sustituyen a los viejos y con los cuales comienza a identificarse. El habla es fundamental puesto que el individuo tiene que reorganizar todo su aparato conversacional y establecer un diálogo distinto que ahora tiene el doble sentido de informar y formar al sujeto, así como de reconstituirlo permanentemente en su nuevo papel de converso.

Las religiones protestantes, en contraste con el catolicismo -cualquiera que sea la corriente de éste-, carecen de la magia de los sacramentos, de la multiplicidad de símbolos visuales que éstos contienen, y no poseen la riqueza iconográfica que caracteriza a los templos católicos, ya que el protestantismo desde su origen erradicó las imágenes y se concentró en la interpretación, lectura, estudio y predi- 


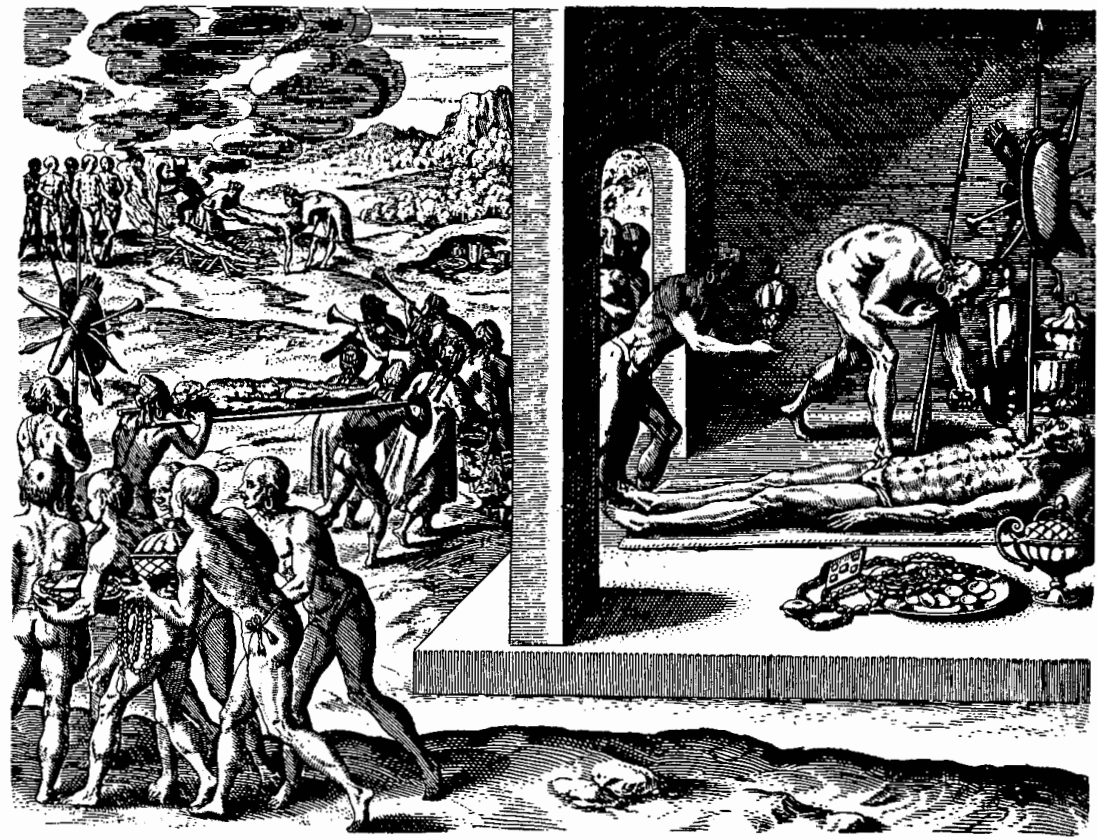

cación de La Palabra. Es decir, en el protestantismo, la retórica religiosa sustituye esa simbología visual y material presente en el catolicismo. Para casi todos los creyentes protestantes y paraprotestantes, una de las constantes que aparecen en las primeras experiencias religiosas son conceptualizadas como el llamado, a través del cual el Espíritu Santo, o el hijo de Dios, habla e interroga a la oveja descarriada, y las respuestas que el sujeto elabora en su interior lo conducen paulatinamente a un autoanálisis en el cual se describe a sí mismo como un perdido en el mundo, un pecador sin rumbo definido, sin metas, que ha vivido a la deriva y que desea darle un nuevo derrotero a su vida. Para que este diálogo interior se dé, es necesario que el sujeto haya tenido interacción previa con otros conversos y en la mayoría de los casos también haya participado en rituales del grupo religioso. A través de estas interacciones, el sujeto se apropia de la retórica religiosa, la va haciendo suya, primero al hablar consigo mismo, y posteriormente desarrolla y perfecciona la retórica y la utiliza para dar a conocer a otros La Palabra. Pero la predicación no tiene un único fin de persuadir a 


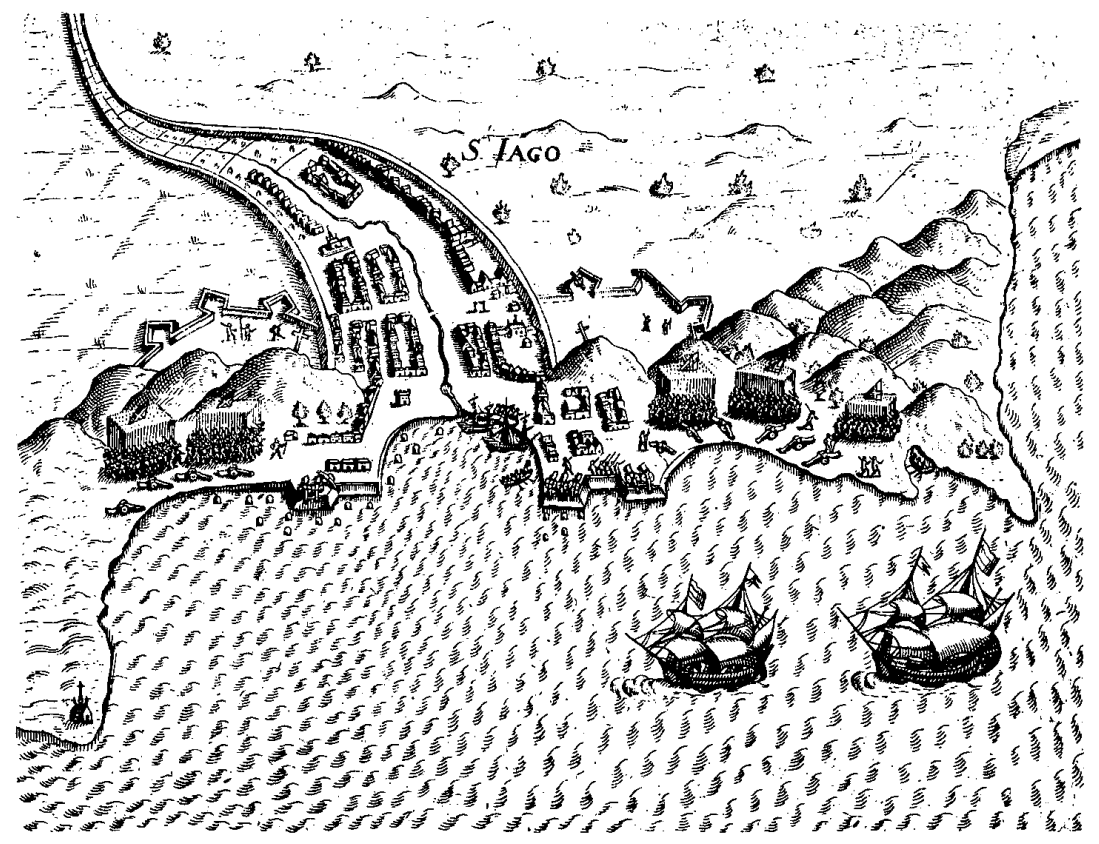

los infieles sobre los beneficios del nuevo credo, sino que además se emplea con el objeto de autoconvencerse a ellos mismos en su nuevo estatus de conversos, ${ }^{4}$ aunque esto último sea en forma poco consciente.

Es en esta parte de la narrativa en donde la mente del sujeto reconstruye su pasado en el marco de la ideología religiosa. El converso, al revivir su pasado, recuerda aquello que tiene sentido para el presente y aquello que según su nuevo marco de interpretación no lo tiene, es reinventado

\footnotetext{
${ }^{4}$ Harding, "Convicted", 1987.
}

y reconstruido en su memoria, a tal grado que cada vez que expresa su testimonio, el individuo ha incorporado nuevos contenidos, excluido otros y aún más, reciclado algunos en una constante actividad de creación y recreación. Estudios sobre el uso de un lenguaje en el interior de una ideología nos revelan que en muchos casos éste sirve para disminuir la angustia o el conflicto, ${ }^{5}$ para reconstruir la nueva identidad, para fortalecer al sujeto en su vida diaria y en sus relaciones con los demás, y desde luego para

\footnotetext{
s Stromberg, "Ideological", 1990.
} 
producir una satisfacción y proveerlos de poder al interior de los mismos sujetos.

La importancia que le atribuyen a la palabra en sus diversas formas tales como la lectura, la predicación, la oración, el canto, el testimonio, el hablar en lenguas, es expresada por los mismos conversos, sobre todo los pentecostales, como lo ilustran los tres fragmentos entresacados de las entrevistas de don Eligio:

Pero hay uno que no es visible: el Espíritu Santo, pero es sentible: él puede influenciar a la persona que está muy mal en su situación de pecado, y bablarle. Pero al leer la palabra de Dios entendí que estaba haciendo algo malo. El Señor me transformó para predicar su palabra.

El vocabulario adquirido implica el aprehender un nuevo conocimiento que se incrementa cotidianamente a través de la lectura de la Biblia, de la escuela dominical, de escuchar la prédica, de narrar sus testimonios, interpretar la presencia de Dios en sus vidas, interpretar los hechos sociales y políticos en el marco de las profecías, de tal forma que los conversos se llegan a transformar en verdaderos expertos en el manejo y uso de la retórica religiosa. En este sentido, podemos ver la conversión desde un plano mucho más amplio que la sola experiencia o vivencia religiosa; como un acto cognitivo a través del cual el individuo no sólo agrega información a la previa, sino que la interconecta entre sí y la reinterpreta. El converso de cualquier religión no es un individuo que se cierre a nuevos conocimientos, sino que los recicla para que encuadren en su marco de referencia, de la misma manera que hacemos todos con los distintos flujos culturales a los que tenemos acceso; como lo hiciera el evocador caso del molinero Menochio en la brillante obra de Carlo Ginsburg, $E l$ queso y los gusanos.

\section{BIBLIOGRAFÍA}

-Fortuny Loret de Mola, Patricia, "Inserción y difusión del sectarismo religioso en el campo yucateco", Yucatán: Historia y Economía, Revista de Análisis Socioeconómico Regional, Universidad de Yucatán, septiembre-octubre, 1982, pp. 3-23.

-Ginsburg, Carlo, El queso y los gusanos. El cosmos según un molinero del siglo XVI, Muchnik Editores, Barcelona, 1994.

-Harding, Susan, "Convicted by the Holy Spirit: the rhetoric of fundamental baptist conversion", American Etbnologist, vol. 14, núm. 1, 1987, pp. 167-182.

-Richardson, James T., "The Active vs passive convert: paradigm conflict in conversion/recruitment research", Journal for the Scientific Study of Religion, 1985, pp. 163-179.

-Spence, Donald, Narrative truth and historical trutb: meaning and interpretation in psychoanalysis, Norton, Nueva York, 1982.

-Stromberg, Peter, "Ideological language in the transformation of identity", American Antbropology, vol. 92, núm. 1, 1990, pp. $42-56$. 